Check for updates

Cite this: RSC Adv., 2019, 9, 27183

Received 1st June 2019

Accepted 22nd August 2019

DOI: $10.1039 / c 9 r a 04158 c$

rsc.li/rsc-advances

\section{Sarcoehrenbergilides D-F: cytotoxic cembrene diterpenoids from the soft coral Sarcophyton ehrenbergi $\uparrow$}

\author{
Mohamed-Elamir F. Hegazy, (D) ab Tarik A. Mohamed, ${ }^{\text {b }}$ Abdelsamed I. Elshamy, ${ }^{\text {cd }}$ \\ Ahmed R. Hamed, ${ }^{b}$ Mahmoud A. A. Ibrahim, (D) e Shinji Ohta, ${ }^{f}$ Akemi Umeyama, ${ }^{d}$ \\ Paul W. Paré (iD *g and Thomas Efferth*a
}

A solvent extract of the soft coral Sarcophyton ehrenbergi afforded cembrene diterpenoids, sarcoehrenbergilid D-F (1-3). Chemical structures were established by modern spectroscopic techniques with absolute stereochemistries determined by circular dichroism (CD) and time-dependent density functional theory electronic CD calculations (TDDFT-ECD). Cytotoxicity activities for 1-3 were evaluated against three human cancer cell lines: lung (A549), colon (Caco-2) and liver (HepG2).

\section{Introduction}

Soft coral of the genus Sarcophyton (subclass Octocorallia; order Alcyonaceae; family Alcyoniidae) contain a diversity of cyclic diterpenes that usually contain ethers, lactones or furanes around a cembrane framework. ${ }^{\mathbf{1}, 2}$ These cembrane diterpenoids exhibit a wide range of structural diversity and biological activity. ${ }^{3-10}$ Cembranoids, the main metabolites identified in the genus Sarcophyton have been shown to serve as an effective chemical defense against natural predators of coral. ${ }^{11}$

The leather coral Sarcophyton ehrenbergi (von Marenzeller, 1886) produces diverse metabolites with distinct chemical structures as well as promising biological activities. ${ }^{\mathbf{8 1 2 - 1 7}}$ Additionally, prostaglandins (PGs) that regulate a broad range of physiological activities, have been isolated from $S$. ehrenbergi. ${ }^{18,19}$

The Red Sea contains a high endemic biota including approximately 50 genera of hermatypic soft coral. ${ }^{20}$ While Red

\footnotetext{
${ }^{a}$ Department of Pharmaceutical Biology, Institute of Pharmacy and Biochemistry, Johannes Gutenberg University, Staudinger Weg 5, 55128 Mainz, Germany

${ }^{b}$ Chemistry of Medicinal Plants Department, National Research Centre, El-Tahrir St., Dokki, Giza12622, Egypt. E-mail: elamir77@live.com; tarik.nrc83@yahoo.com; n1ragab2004@yahoo.com

${ }^{c}$ Natural Compound Chemistry Department, National Research Centre, El-Tahrir St., Dokki, Giza 12622, Egypt. E-mail: elshamynrc@yahoo.com

${ }^{d}$ Faculty of Pharmaceutical Sciences, Tokushima Bunri University, Yamashiro-cho, Tokushima, 770-8514, Japan.E-mail: umeyama@ph.bunri-u.ac.jp

${ }^{e}$ Computational Chemistry Laboratory, Chemistry Department, Faculty of Science, Minia University, Minia 61519, Egypt.E-mail: m.ibrahim@compchem.net

${ }^{f}$ Graduate School of Biosphere Science, Hiroshima University, 1-7-1 Kagamiyama, Higashi-Hiroshima 739-8521, Japan.E-mail: ohta@hiroshima-u.ac.jp

${ }^{g}$ Department of Chemistry and Biochemistry, Texas Tech University, Lubbock, TX 79409, USA

$\dagger$ Electronic supplementary information (ESI) available: Fig. S1-S21: HR-ESI-MS, 1D, and 2D NMR spectra of compounds 1-3. See DOI: 10.1039/c9ra04158c
}

Sea marine invertebrates have been historically under-reported within the scientific literature, intensive investigation of Red Sea marine life has occurred over the past ten years. ${ }^{\mathbf{8 2 1 - 2 3}}$ To continue efforts to identify new marine metabolites from Red Sea soft coral, ${ }^{6-8,22-24}$ herein we report three cembrene diterpenoids isolated from S. ehrenbergi (Fig. 1). Absolute stereochemistry of the newly reported compounds was determined by time-dependent density functional theory-electronic circular dichroism (TDDFT-ECD) calculations. All isolated metabolites were probed against three human cancer cell lines.

\section{Results and discussion}

Freshly collected $S$. ehrenbergi were rapidly frozen by placing in $\mathrm{a}-20{ }^{\circ} \mathrm{C}$ chamber and kept frozen till time of extraction. The chromatographic separation of the methylene chloride : methanol $(1: 1)$ extract yielded three cembrene diterpenoids derivatives (Fig. 1).

Compound 1 was isolated as a white powder with an optical rotation of $[\alpha]_{\mathrm{D}}^{25}+10.1\left(c 0.02, \mathrm{CHCl}_{3}\right)$. The molecular formula $\mathrm{C}_{21} \mathrm{H}_{32} \mathrm{O}_{5}$ was determined by high-resolution electron ionization mass spectrum (HREIMS) $\left(\mathrm{m} / \mathrm{z} 346.2127\left[\mathrm{M}-\mathrm{H}_{2} \mathrm{O}\right]^{+}\right.$, calcd 346.2149).

The IR spectrum showed absorption bands at $\nu_{\max }$ $3450 \mathrm{~cm}^{-1}$ and $1754 \mathrm{~cm}^{-1}$ for hydroxyl and keto groups, respectively. The ${ }^{13} \mathrm{C}$ NMR and distortion less enhancement by polarization transfer (DEPT) spectrum showed 21 carbon signals, classified as five methyls, six methylenes, four methines and six quaternary carbons (Table 1). Additionally, four oxygenated carbons at $\delta_{\mathrm{C}} 76.2(\mathrm{dC}), 78.0(\mathrm{dC}), 78.5(\mathrm{dC})$ and 78.1 $(\mathrm{sC})$, four olefinic carbon signals at $\delta_{\mathrm{C}} 119.5,121.8,147.0$ and 163.0. These functionalities were obtained by ${ }^{1} \mathrm{H}$ NMR analysis: oxygenated proton signals at $\delta_{\mathrm{H}} 3.57$ (brd; $\left.J=10.0 \mathrm{~Hz}\right), \delta_{\mathrm{H}} 3.14$ (brd, $J=5.0 \mathrm{~Hz}), \delta_{\mathrm{H}} 5.45(\mathrm{~d} ; J=10.0 \mathrm{~Hz})$; four methyl singlets at 


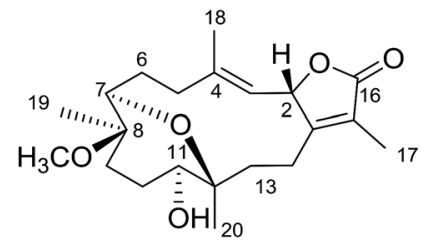

1

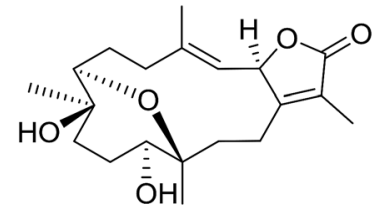

2

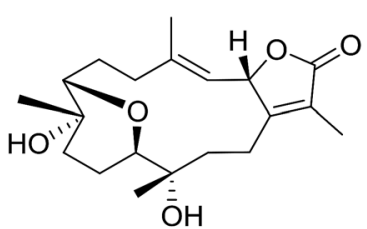

3

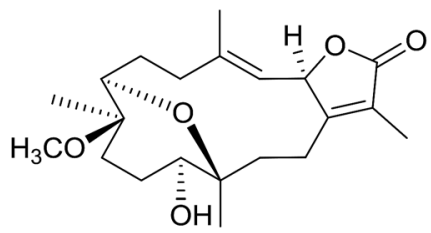

Sarcoehrenbergilid A [23]

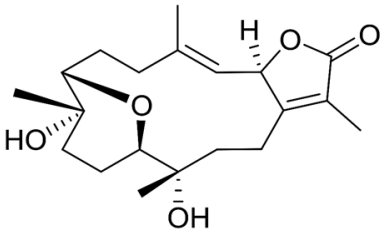

sarcophyolide E [25]

Fig. 1 Structures of metabolites 1-3.

$\delta_{\mathrm{H}} 2.02 \mathrm{~s}, 1.83 \mathrm{~s}, 1.11 \mathrm{~s}$ and 1.03 , as well as, one methyl of a methoxy group at $\delta_{\mathrm{H}} 3.20 \mathrm{~s}$; olefinic signal at $\delta_{\mathrm{H}} 5.14(\mathrm{~d} ; J=$ $10.0 \mathrm{~Hz}$ ) signed for a tri-substituted double bond (Table 1). 1D and 2D NMR spectroscopic data comparison (Table 1) closely corresponded to those of previously isolated metabolites from Sarcophyton species as well as a previously isolated skeleton by Hegazy et al., 2017 (ref. 5-13, 22 and 23) (Fig. 2).

The signal at $\delta_{\mathrm{H}} 5.45(\mathrm{~d} ; J=10.0 \mathrm{~Hz})$ correlated with a proton signal at $\delta_{\mathrm{H}} 5.14(\mathrm{~d}, J=10.0 \mathrm{~Hz})$ and quaternary olefinic carbons at $\delta_{\mathrm{C}} 147.0$ and $\delta_{\mathrm{C}} 163.0$ in DQF-COSY and HMBC (Fig. 2), respectively, allowed for the assignments of $\mathrm{H}-2, \mathrm{H}-3, \mathrm{C}-4$ and C-
1, respectively. ${ }^{8-10,23-25}$ Correlations in the HMBC spectrum showed several informative connections: $\mathrm{H}-3$ to carbon signals at $\delta_{\mathrm{C}} 13.6$ (q, olefinic) $\delta_{\mathrm{C}} 34.6(\mathrm{t})$, allowed for the assignment of $\mathrm{H}-18\left(\delta_{\mathrm{H}} 2.02, \mathrm{~s}\right)$ and $\mathrm{H}-5\left(\delta_{\mathrm{H}} 2.37\right.$, brd, $\left.J=14.0\right)$, respectively; methyl signal $\delta_{\mathrm{H}} 1.83$ (s) to C-1 and carbon signal at $\delta_{\mathrm{C}} 174.0$ $(\mathrm{C}=\mathrm{O})$ attributed to $\mathrm{H}-17$ and $\mathrm{C}-16$, respectively as well as supporting the location of $\mathrm{C}-1 / \mathrm{C}-2$ lactone ring; methyl singlet at $\delta_{\mathrm{H}} 1.11$ to $\delta_{\mathrm{C}} 73.5(\mathrm{C}-7), \delta_{\mathrm{C}} 37.0$ and 78.5 allowed for the location of $\mathrm{H}_{3}-19\left(\delta_{\mathrm{C}} 13.6\right)$, C-9 and $\mathrm{C}-8$, respectively; the oxygenated broad doublet at $\delta_{\mathrm{H}} 3.57\left(\delta_{\mathrm{C}} 79.0\right)$ to C-9 and C-20, was assigned to $\mathrm{H}-11$. The assignment of $\mathrm{H}-7, \mathrm{H}_{2}-6$ and $\mathrm{C}-5$

Table $1{ }^{1} \mathrm{H}(500 \mathrm{MHz})$ and ${ }^{13} \mathrm{C}(125 \mathrm{MHz})$ NMR data for compound $1-3^{a}(\delta$ in ppm, $\mathrm{J}$ in Hz)

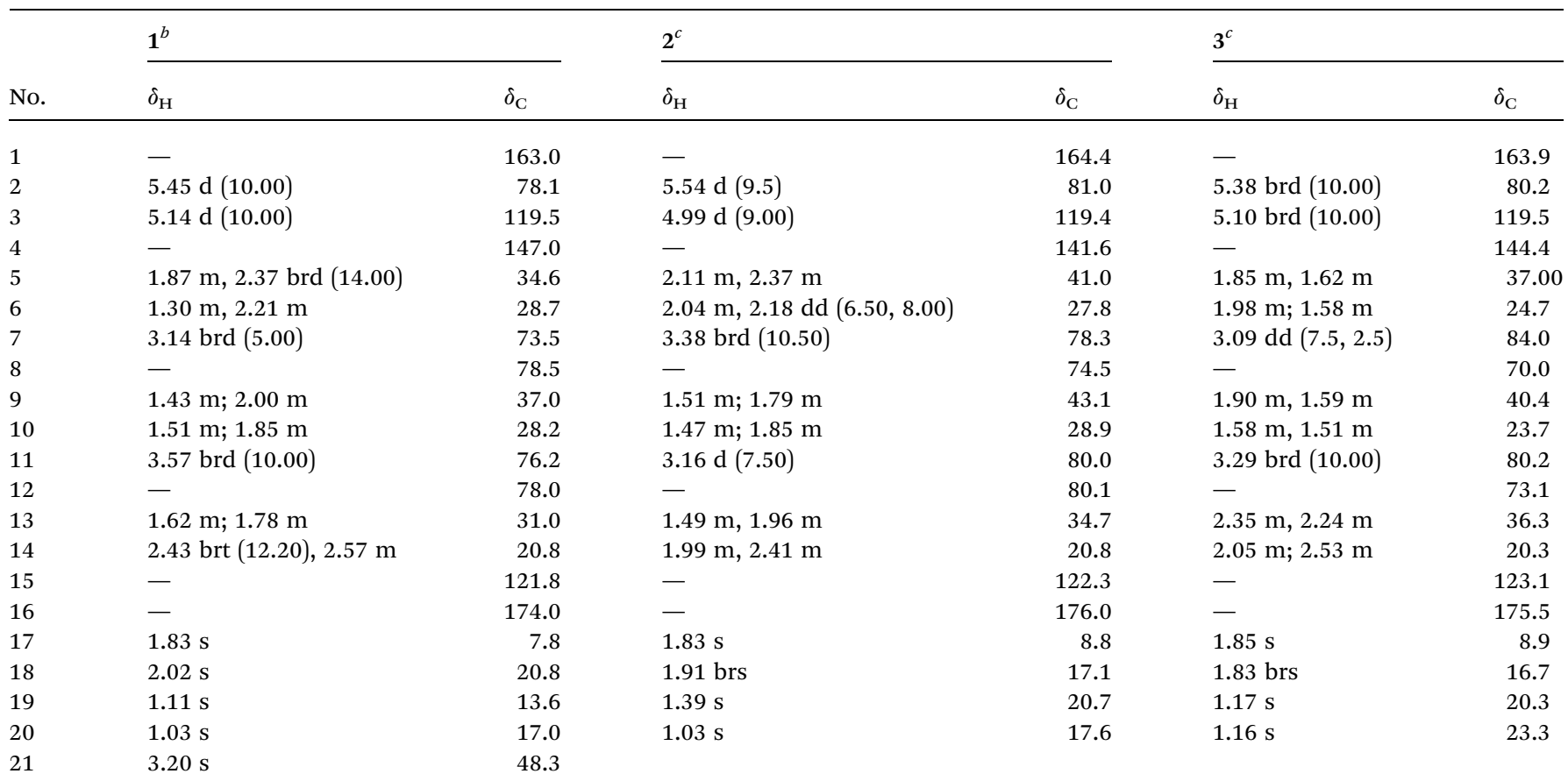

${ }^{a} J$ values (Hz) in parentheses, obtained at 500 and $125 \mathrm{MHz}$ for ${ }^{1} \mathrm{H}$ and ${ }^{13} \mathrm{C}$ NMR, respectively. ${ }^{b}$ Recorded in $\mathrm{CDCl}_{3} \cdot{ }^{c} \mathrm{Recorded}$ in $\mathrm{CDCl}_{3}-\mathrm{CD}_{3} \mathrm{OD}$ $(9: 1)$. 


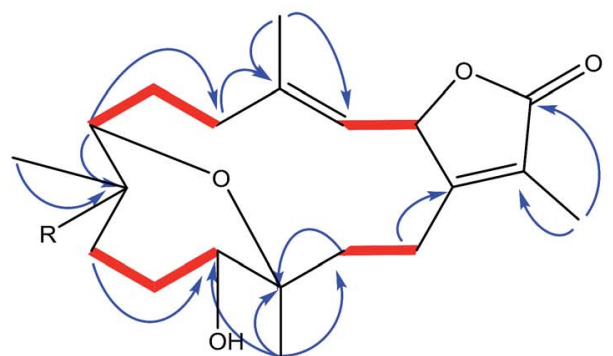

$1 \mathrm{R}=\mathrm{OCH}_{3}$

$2 \mathrm{R}=\mathrm{OH}$

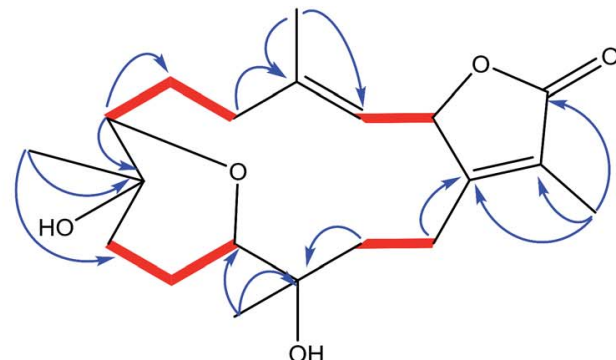

3

Fig. 2 Selected ${ }^{1} \mathrm{H}-{ }^{1} \mathrm{H}$ COSY $(\square)$ and $\mathrm{HMBC}(\Longrightarrow$ ) correlations of 1-3.

was detected through the correlation of the oxygenated methine signal at $\delta_{\mathrm{H}} 3.14(\mathrm{brd}, J=5.0)$ to a methylene multiplet at $\delta_{\mathrm{H}}$ $1.30 / 2.21$ and a carbon signal at $\delta_{\mathrm{C}} 34.6$ in DQF-COSY and HMBC, respectively. Additionally, a correlation was detected in DQF-COSY between $\mathrm{H}-13\left(\delta_{\mathrm{H}} 1.78, \mathrm{~m}\right)$ and $\mathrm{H}-14\left(\delta_{\mathrm{H}} 2.43\right.$, brt, $J=$ 12.2) as well as to C-20 in HMBC analyses (Fig. 2). An HMBC correlation established the site of a methoxy group $\left(\delta_{\mathrm{H}} 3.20 \mathrm{~s}, \delta_{\mathrm{C}}\right.$ $48.3 \mathrm{q})$ at C-8.

The planar structure assignment of $\mathbf{1}$ and the $\mathrm{C}-7 / \mathrm{C}-12$ ether linkage were proposed by 1D, 2D NMR and HREIMS data. The data comparison with those of sarcoehrenbergilid A, as previously reported ${ }^{23}$ suggested that $\mathbf{1}$ and sarcoehrenbergilid $\mathrm{A},{ }^{23}$ differ only in stereochemistry.

The NOESY spectrum revealed that a $\gamma$-lactone at $\mathrm{H}-2\left(\delta_{\mathrm{H}} 5.45\right.$, $\mathrm{d}, J=10.0 \mathrm{~Hz})$ correlated with $\mathrm{CH}_{3}-18\left(\delta_{\mathrm{H}} 2.02, \mathrm{~s}\right)$; a vicinal coupling with $\mathrm{H}-3$ established a trans configuration and a $\beta$ orientation for $\mathrm{H}-2 .{ }^{8}$ NOSEY correlations were observed between three methyl groups with alpha protons (e.g., $\mathrm{CH}_{3}-20$ with $\mathrm{H}-10 \mathrm{a}$, $\mathrm{CH}_{3}-19$ with $\mathrm{H}-6 \mathrm{a} / \mathrm{H}-10 \mathrm{a}$, and $\mathrm{CH}_{3}-17$ with $\mathrm{H}-14 \mathrm{a}$ ) (Fig. 3). $\mathrm{H}-7$ and $\mathrm{H}-11$ was assigned to a $\beta$-configuration based on NOSEY correlations with $\mathrm{H}-5 \mathrm{~b}$ and $\mathrm{H}-14 \mathrm{~b}$, respectively. Absolute configuration was established by experimental and TDDFT-simulated ECD spectra. All possible conformations of $\mathbf{1}$ within energy window of $10 \mathrm{kcal} \mathrm{mol}^{-1}$ were generated and optimized at B3LYP/6-31G* level of theory. The first 50 excitation states were then computed based on time-dependent density-functional theory (TDDFT) at B3LYP/6$31 \mathrm{G}^{*}$ level in methanol by the PCM model. The generated TDDFTECD spectra were Boltzmann-weighted and compared to the experimental spectrum (Fig. 4). The TDDFT-simulated ECD spectrum was in a good agreement with the corresponding experimental ECD spectra (Fig. 4). This comparison revealed the absolute configuration and therefore $\mathbf{1}$ was assigned as $2 S, 16: 7 S, 12 S$-diepoxy-11R-hydroxy-8R-methoxy-16-keto-cembra$1 Z, 3 E$-diene (sarcoehrenbergilid D).
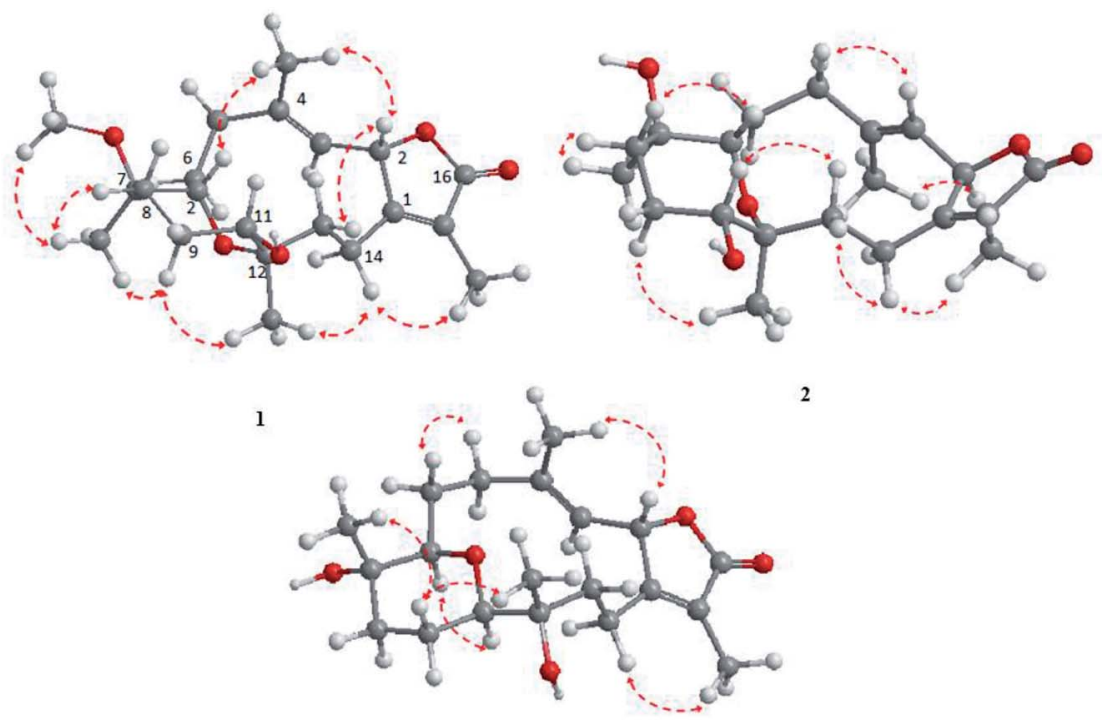

Fig. 3 Selected NOESY correlations for 1-3. 


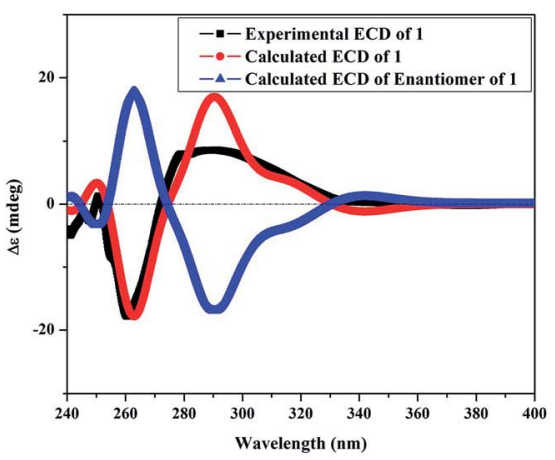

(a)

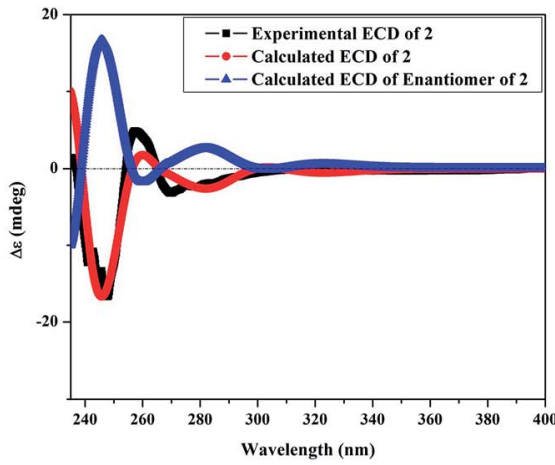

(b)

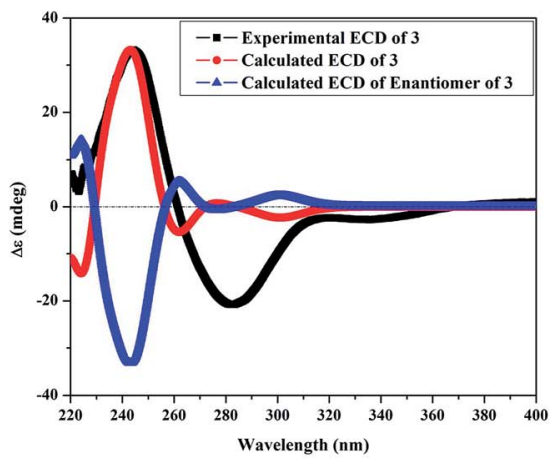

(c)

Fig. 4 Experimental electronic circular dichroism (ECD in MeOH): (a) 1 compared with the TDDFT-simulated ECD spectra of 2S,7S,12S-diepoxy$11 R$-hydroxy-8R-methoxy-16-keto-cembra-1Z,3E-diene and 2R,7R,12R-diepoxy-11S-hydroxy-8S-methoxy-16-keto-cembra-1E,3Z-diene; (b) 2 compared with the TDDFT-simulated ECD spectra of $2 R, 7 S, 12 S$-diepoxy-11R-hydroxy-8R-methoxy-16-keto-cembra-1Z,3E-diene and $2 S, 7 R, 12 R$-diepoxy-11S-hydroxy-8S-methoxy-16-keto-cembra-1E,3Z-diene; and (c) 3 compared with the TDDFT-simulated ECD spectra of $2 S, 7 R, 11 R$-diepoxy-12S-hydroxy-8S-methoxy-16-keto-cembra-1Z,3E-diene and 2R,7S,11S-diepoxy-12R-hydroxy-8R-methoxy-16-ketocembra-1E,3Z-diene.

Compound 2 was isolated as a white powder with a negative

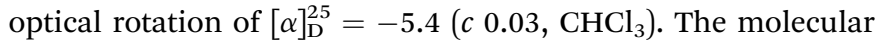
formula $\left(\mathrm{C}_{20} \mathrm{H}_{30} \mathrm{O}_{5}\right)$ was detected by high resolution electron ionization (HREIMS) spectrum $\left(\mathrm{m} / \mathrm{z} 350.2094[\mathrm{M}]^{+}\right.$, calcd 350.2093). HREIMS analysis exhibited a molecular ion peak at $\mathrm{m} / z$ 350.2094 $[\mathrm{M}]^{+}$(calcd) The IR spectrum showed characteristic bands at $\nu_{\max } 3445 \mathrm{~cm}^{-1}$ and $1747 \mathrm{~cm}^{-1}$ for hydroxyl and keto groups, respectively. The ${ }^{13} \mathrm{C}$ NMR spectrum revealed twenty carbon signals (Table 1) classified by DEPT as six quaternary, four methines, six methylenes and four methyls carbons. 1D and 2D NMR spectroscopic data were quite close to sarcoehrenbergilid $\mathrm{A}^{23}$ a formerly isolated diterpenoid from $S$. ehrenbergi except for an absence of methoxyl groups. For 2 there is an upfield carbon signal at $\delta_{\mathrm{C}} 74.5$ and a downfield methyl signal at $\delta_{\mathrm{C}} 20.7$ for $\mathrm{C}-8$ and $\mathrm{CH}_{3}-19$, respectively.

Stereochemistry was established based on coupling constants and NOESY experiments (Fig. 3). NOESY correlation indicated that $\mathbf{2}$ has the same relative stereochemistry as sarcoehrenbergilid A. $^{23}$ To determine absolute configuration, TDDFT-ECD calculations were performed on the $2 R, 7 S, 8 R, 11 R, 12 S$ - and $2 S, 7 R, 8 S, 11 S, 12 R$-enantiomers. The final Boltzmann-weighted TDDFT-ECD spectra were then compared to the corresponding experimental ECD curve (Fig. 4). According to the data depicted in Fig. 4 , the $2 R, 7 S, 8 R, 11 R, 12 S$-enantiomer reproduced all the transitions of the experimental ECD spectrum. Therefore, 2 was assigned as $2 R, 16: 7 S, 12 S$-diepoxy$11 R$-hydroxy- $8 R$-methoxy-16-keto-cembra-1Z,3E-diene (sarcoehrenbergilid E). Compound 3 was isolated as a colorless oil with

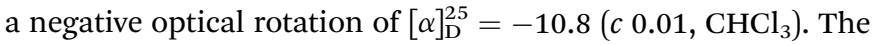
molecular formula of $\mathrm{C}_{20} \mathrm{H}_{30} \mathrm{O}_{5}$ was detected by high resolution electron ionization (HREIMS) analysis $(\mathrm{m} / \mathrm{z} 332.1993$ [M $\mathrm{H}_{2} \mathrm{O}^{+}$], calcd 332.1998).

The IR spectrum showed characteristic bands at $\nu_{\max }$ $3445 \mathrm{~cm}^{-1}$ and $1747 \mathrm{~cm}^{-1}$ for hydroxyl and keto groups, respectively. The ${ }^{13} \mathrm{C}$ NMR spectrum (Table 1 ) showed 20 carbon resonances classified by DEPT analysis as four methyls, six methylenes, four methines and six quaternary carbons. The 1D $\left({ }^{1} \mathrm{H},{ }^{13} \mathrm{C}\right)$ as well as $2 \mathrm{D}$ NMR $\left({ }^{1} \mathrm{H}^{-1} \mathrm{H}\right.$ COSY, HSQC, and HMBC) (Fig. 2) spectroscopic data closely matches a previously reported cemberene compound. ${ }^{26}$ The NOESY correlation (Fig. 3) as well as the ${ }^{1} \mathrm{H}$ and ${ }^{13} \mathrm{C}$ NMR analyses indicated that 3 is a C-2 epimer of the previously isolated sarcophyolide $\mathrm{E}^{26}$ through the clear difference in downfield shift of $\mathrm{H}-3\left(\delta_{\mathrm{H}} 5.10, \mathrm{~d}, J=10.0\right)$. Additionally, several carbon signals showed downfield chemical shift in comparison of sarcophyolide $\mathrm{E}: \delta_{\mathrm{C}} 37.0 / 36.2$ (C-5), 73.1/ 71.8 (C-12), 123.1/121.7 (C-15), and 175.5/174.9 (C-17), respectively. The carbon signals at $\delta_{\mathrm{C}} 163.9$ (C-1) and 36.3 (C-13) showed upfield chemical shift in comparison with sarcophyolide $\mathrm{E}\left[\delta_{\mathrm{C}} 165.8(\mathrm{C}-1)\right.$ and $\left.37.3(\mathrm{C}-13)\right]$.

The relative configuration for 3 was established based on coupling constants and NOESY experiments (Fig. 3). A NOE correlation between $\mathrm{H}-7\left(\delta_{\mathrm{H}} 3.09 \mathrm{dd}, J=7.5,2.5\right)$ and $\mathrm{H}-11\left(\delta_{\mathrm{H}}\right.$ $3.29 \mathrm{brd}, J=10.0)$ established an alpha linkage for the ether bridge between C-7 and C-11. The NOE correlations between $\mathrm{H}-3$ and the $\gamma$-lactone-(H-2) as well as vicinal coupling constant indicated a trans-geometry for $\mathrm{H}-2$ and $\mathrm{H}-3$ of the olefinic bond (Fig. 3). As expected, the experimental ECD for 3 and published compound, sarcophyolide $\mathrm{E}^{, 26}$ showed inverted direction for positive and negative cotton effect as well as optical rotation (Fig. 4). These data indicated that 3 is the C-2 epimer of sarcophyolides E. Thus, 3 was confirmed to be $\quad 2 S, 16: 7 R, 11 R$-diepoxy-12S-hydroxy- $S S$-methoxy-16-ketocembra-1Z,3E-diene (sarcoehrenbergilid F).

Isolated metabolites 1-3 were tested for cytotoxic activity toward lung (A549), colon (Caco-2) and liver (HepG2) human cancer cell lines based on an MTT reduction assay (Fig. 5). Compounds 1-3 showed most potent activity toward A549 cells with $\mathrm{IC}_{25}$ values of $23.3,27.3$, and $25.4 \mu \mathrm{M}$, respectively. Compound 2 and 3 showed weaker activity toward liver (HepG2) human cancer cell lines with $\mathrm{IC}_{25}$ values of 22.6 and $31.8 \mu \mathrm{M}$, respectively. The treated human colon cancer cells (Caco-2) cell viability was over $100 \%$ for all the isolated compounds $\left(\mathrm{IC}_{25}>\right.$ 


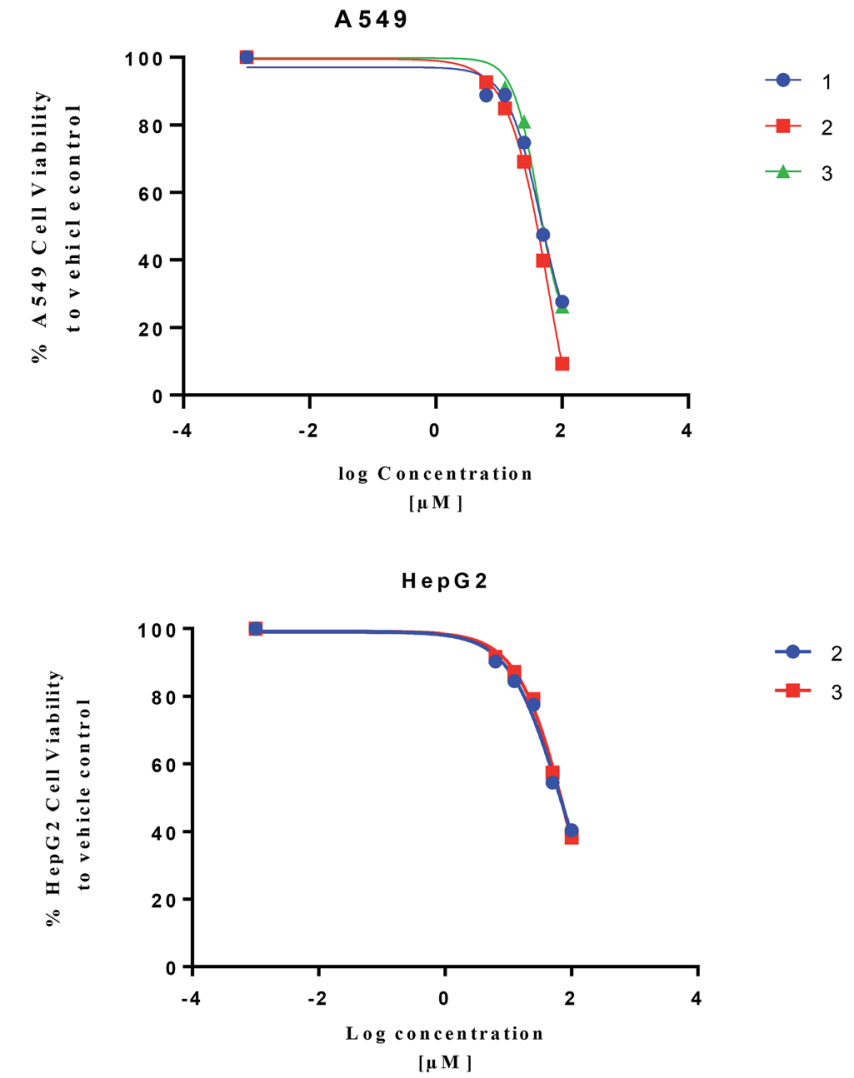

Fig. 5 Cytotoxicity assay of 1-3 based on MTT-reduction assay.

$100 \mu \mathrm{M})$. Since primary necrosis is not easily differentiated from secondary necrosis that occurs with apoptosis,${ }^{27}$ the mode of action will not be considered. To differentiate these distinct biological events requires apoptotic assays accompanying necrosis measurements. A combined necrosis/apoptotic timecourse will be presented in a subsequent study to elaborate on mode of action.

\section{Experimental section}

\subsection{General experimental procedures}

Circular dichroism was measured on JASCO 810 spectropolarimeter. HREIMS data were collected on a JEOL JMS-700 instrument (Tokyo, Japan). NMR spectra were recorded on a Bruker 500 NMR spectrometer (Japan). JASCO P-2200 polarimeter and JASCO FT/IR-6300 spectrometer was used for optical rotation and infrared measurements, respectively.

Normal-phase silica gel 60 (230-400) column chromatography (CC) as well as aluminum TLC plates (silica gel $60 \mathrm{~F}_{254}$ ) (Merck, Darmstadt, Germany) were used for purification and monitoring spotting, respectively. A $\mathrm{H}_{2} \mathrm{SO}_{4}: \mathrm{MeOH}$ (1:9) spraying reagent was used for spot visualization after heating. HPLC purification was performed using Shimadzu HPLC-RID$10 \mathrm{~A}$ with YMC-Pack ODS-A analytical $(250 \times 4.6 \mathrm{~mm}$ i.d. $)$ and preparative $(250 \times 20 \mathrm{~mm}$ i.d.) columns (YMC, Tokyo, Japan) for separation.

\subsection{Animal material}

Sarcophyton ehrenbergi coral was collected from the Red Sea on the Egyptian coast at Hurghada, in March 2016 and identified by $\mathrm{Dr} \mathrm{M}$. Al-Hammady. A voucher specimen (03RS27/1) was deposited in the National Institute of Oceanography and Fisheries, marine biological station, Hurghada, Egypt.

\subsection{Extraction and isolation}

Sliced frozen soft coral ( $2 \mathrm{~kg}$, total wet weight) were extracted with $\mathrm{CH}_{2} \mathrm{Cl}_{2}: \mathrm{MeOH}(1: 1, \mathrm{v} / \mathrm{v})$ at room temperature $(3 \mathrm{~L} \times 4$ times). Isolation protocol was performed as described previously by Hegazy et al., 2017 (ref. 23) to afford 1 (5.5 mg), 2 (4 mg) and 3 (6 mg).

3.3.1 Sarcoehrenbergilid D (1). White powder; $[\alpha]_{\mathrm{D}}^{25}+10.8(c$ $\left.0.02, \mathrm{CHCl}_{3}\right)$; FT-IR $(\mathrm{KBr}) \nu_{\max }: 3435,2941,1748,1462$, and $1224 \mathrm{~cm}^{-1} ;{ }^{1} \mathrm{H}$ and ${ }^{13} \mathrm{C}$ NMR data, see Table 1; HREIMS $\mathrm{m} / \mathrm{z}$ $346.2127\left[\mathrm{M}-\mathrm{H}_{2} \mathrm{O}\right]^{+}$(calcd 346.2149).

3.3.2 Sarcoehrenbergilid E (2). White powder; $[\alpha]_{\mathrm{D}}^{25}-5.4(c$ $\left.0.03, \mathrm{CHCl}_{3}\right)$; FT-IR (KBr) $\nu_{\text {max }}: 3433,2938,1743,1446$, and $1218 \mathrm{~cm}^{-1} ;{ }^{1} \mathrm{H}$ and ${ }^{13} \mathrm{C}$ NMR data, see Table 1; HREIMS $\mathrm{m} / \mathrm{z}$ $350.2094[\mathrm{M}]^{+}$(calcd 350.2093).

3.3.3 Sarcoehrenbergilid $\mathbf{F}$ (3). White amorphous powder; $[\alpha]_{\mathrm{D}}^{25}-10.8\left(c 0.01, \mathrm{CHCl}_{3}\right)$; FT-IR (KBr) $\nu_{\max }: 3441,2932,1742$, 1448, and $1229 \mathrm{~cm}^{-1} ;{ }^{1} \mathrm{H}$ and ${ }^{13} \mathrm{C}$ NMR data, see Table 1; HREIMS $m / z 332.1993\left[\left(\mathrm{M}-\mathrm{H}_{2} \mathrm{O}\right)^{+}\right]$(calcd 332.1998).

\subsection{Biological activity}

3.4.1 Cell lines. Three human cancer cell lines, A549 (nonsmall cell lung adenocarcinoma), Caco-2 (colon adenocarcinoma) and HepG2 (hepatocellular carcinoma) (ATCC $®$ ) were assayed with the purified compounds. All cell lines were cultured in Dulbecco's modified Eagle's medium (DMEM) supplemented with $10 \%$ (FBS fetal bovine serum), $1 \%$ penicillin and incubated in $5 \% \mathrm{CO}_{2}$ at $37{ }^{\circ} \mathrm{C}$.

3.4.2 MTT cytotoxicity assay. The cytotoxicity of tested compounds was investigated by a MTT assay. Cell lines were seeded and incubated overnight allowing cell adhesion to the plate well $\left(5 \times 10^{3}\right.$ cells per well; 96-well plate in a volume of 100 $\mu \mathrm{L})$. To generate concentration-dependent curves, sample concentration was varied $(100,50,25,12.5,6.25 \mu \mathrm{M})$ for a total well volume of $200 \mu \mathrm{L}$ for $48 \mathrm{~h}$. MTT solution $\left(5 \mathrm{mg} \mathrm{ml}^{-1}\right)$ was added $\left(100 \mu \mathrm{L}\right.$ per well) for $90 \mathrm{~min}$ before measurements. ${ }^{28,29}$ After medium removal, dark blue formazan crystals formed in viable cells were dissolved in $100 \mu \mathrm{L}$ of DMSO, followed by shaking for $10 \mathrm{~min}(200 \mathrm{rpm})$. The absorbance was recorded at $492 \mathrm{~nm}$ using a microplate reader (Sunrise ${ }^{\mathrm{TM}}$ microplate reader, Tecan Austria Gmbh, Grödig, Austria) for cell viability measurement. $\mathrm{IC}_{25}$ values were expressed as a concentration of tested compound that inhibits $50 \%$ cell growth in comparison with a vehicle control (quadrate to octuplet treatment) by nonlinear regression model analyses using GraphPad Prism ${ }^{\circledR} \mathrm{v}$ 6.0 software. 


\subsection{Computational functional theory calculations}

Conformational analysis was performed using Omega2 software $^{30}$ to obtain the possible conformers for 1-3 within energy window value of $10 \mathrm{kcal} \mathrm{mol}^{-1}$. All resulting conformers were optimized at B3LYP/6-31G* level of theory using Gaussian09 software. ${ }^{30}$ Frequency calculations were then performed on the optimized structures to ensure the nature of the local minima as well as to estimate the Gibbs free energies. Time-dependent density functional theory (TDDFT) calculations with incorporating a polarizable continuum model (PCM) using methanol as a solvent were carried out at the B3LYP/6-31G* level of theory to calculate the first fifty excitation states. Electronic circular dichroism (ECD) spectra were finally generated using SpecDis 1.71 (SpecDis 2017 (ref. 31 and 32)) by applying Gaussian band shapes with sigma $=0.20-30 \mathrm{eV}$. The generated ECD spectra were Boltzmann-averaged.

\section{Conclusions}

Cembrene diterpenoids (1-3) were isolated and identified from the $S$. ehrenbergi soft coral. The isolated compounds were tested against three human cancer cell lines, which resulted in 2 being the most potent compound against lung A549 cancer cell. The absolute stereochemistry of 1-3 were confirmed by comparing experimental and TDDFT-simulated ECD spectra.

\section{Conflicts of interest}

There are no conflicts to declare.

\section{Acknowledgements}

This work was supported by Alexander von Humboldt Foundation (Georg Förster Research Fellowship) to MEFH, National Research Centre, Egypt and the Welch Foundation (D-1478). Dr Elshamy gratefully acknowledges the Takeda Science Foundation, Japan for the financial support. Computational work was completed in part with resources supported by the Science and Technology Development Fund, STDF, Egypt, Grants No. 5480 \& 7972.

\section{Notes and references}

1 B. Yang, X.-F. Zhou, X.-P. Lin, J. Liu, Y. Peng, X.-W. Yang and Y. Liu, Cembrane diterpenes chemistry and biological properties, Curr. Org. Chem., 2012, 16, 1512-1539.

2 M. Kobayashi, T. Nakagawa and H. Mitsuhashi, Marine terpenes and terpenoids. I. Structures of four cembranetype diterpenes: sarcophytol-A, sarcophytol-A acetate sarcophytol-B, and sarcophytonin-A, from the soft coral, Sarcophyton glaucum, Chem. Pharm. Bull., 1979, 27, 23822387.

3 B. Yang, J. Liu, J. Wang, S. Liao and Y. Liu, Cytotoxic cembrane diterpenoids, Handbook of anticancer drugs from marine origin, ed. S.-K. Kim, Springer International Publishing, Switzerland, 2015.
4 R. Abou El-Ezz, S. Ahmed, M. Radwan, N. Ayoub, M. Afifi, S. Ross, P. Szymanski, H. Fahmy and S. Khalifa, Bioactive cembranoids from the Red Sea soft coral Sarcophyton glaucum, Tetrahedron Lett., 2013, 54, 989-992.

5 L. Liang and Y. Guo, Terpenes from the soft corals of the genus Sarcophyton: chemistry and biological activities, Chem. Biodiversity, 2013, 10, 2161-2196.

6 M. E. Hegazy, A. A. El-Beih, A. Y. Moustafa, A. A. Hamdy, M. A. Alhammady, R. M. Selim, M. Abdel-Rehim and P. W. Paré, Cytotoxic cembranoids from the Red Sea soft coral Sarcophyton glaucum, Nat. Prod. Commun., 2011, 6, 1809-1812.

7 M. E. Hegazy, T. A. Mohamed, F. A. Abdel-Latif, M. Alsaid, A. A. Shahat and P. W. Paré, Trochelioid A and B, new cembranoid diterpenes from the Red Sea soft coral Sarcophyton trocheliophorum, Phytochem. Lett., 2013, 6, 383386.

8 A. Elkhateeb, A. El-Beih, A. Gamal-Eldeen, M. Alhammady, S. Ohta, P. Paré and M. E. Hegazy, New terpenes from the Egyptian soft coral Sarcophyton ehrenbergi, Mar. Drugs, 2014, 12, 1977-1986.

9 X.-H. Yan, Z.-Y. Li and Y.-W. Guo, Further new cembranoid diterpenes from the Hainan soft coral Sarcophyton latum, Helv. Chim. Acta, 2007, 90, 1574.

10 X.-H. Yan, L.-Y. Feng and Y.-W. Guo, Further new cembrane diterpenes from the Hainan soft coral Sarcophyton latum, Chin. J. Chem., 2008, 26, 150.

11 M. E. Hegazy, T. A. Mohamed, M. A. Alhammady, A. M. Shaheen, E. H. Reda, A. I. Elshamy, M. Aziz and P. W. Paré, Molecular architecture and biomedical leads of terpenes from Red Sea marine invertebrate, Mar. Drugs, 2015, 13, 3154-3181.

12 B. F. Bowden, J. C. Coll, W. Hicks, R. Kazlauskas and S. J. Mitchell, Studies of Australian soft corals. X. The isolation of epoxyisoneocembrene-A from Sinulariagrayi and isoneocembrene-A from Sarcophyton ehrenberg, Aust. J. Chem., 1978, 31, 2707-2712.

13 G. M. König and A. D. Wright, New cembranoid diterpenes from the soft coral Sarcophyton ehrenbergi, J. Nat. Prod., 1998, 61, 494-496.

14 K. H. Shaker, M. Mueller, M. A. Ghani, H. M. Dahse and K. Seifert, Terpenes from the soft corals Litophyton arboreum and Sarcophyton ehrenbergi, Chem. Biodiversity, 2010, 7, 2007-2015.

15 S.-Y. Cheng, S.-K. Wang, S.-F. Chiou, C.-H. Hsu, C.-F. Dai, M. Y. Chiang and C.-Y. Duh, Cembranoids from the octocoral Sarcophyton ehrenbergi, J. Nat. Prod., 2010, 73, 197-203.

16 S.-K. Wang, M.-K. Hsieh and C.-Y. Duh, Three new cembranoids from the Taiwanese soft coral Sarcophyton ehrenbergi, Mar. Drugs, 2012, 10, 1433-1444.

17 S.-K. Wang, M.-K. Hsieh and C.-Y. Duh, New diterpenoids from soft coral Sarcophyton ehrenbergi, Mar. Drugs, 2013, 11, 4318-4327.

18 Z. B. Cheng, Y. L. Deng, C. Q. Fan, Q. H. Han, S. L. Lin, G. H. Tang, H. B. Luo and S. Yin, Prostaglandin Derivatives: Nonaromatic Phosphodiesterase-4 Inhibitors 
from the Soft Coral Sarcophyton ehrenbergi, J. Nat. Prod., 2014, 77, 1928-1936.

19 V. C. Sekhar, C. B. Rao, H. Ramana, M. M. K. Kuwar and D. V. Rao, New Prostaglandins from the soft coral Sarcophyton ehrenbergi marengeller of Andaman and Nicobar Islands of Indian ocean, Asian J. Chem., 2010, 22, 5353-5358.

20 A. J. Edwards and S. M. Head, Key Environments-Red Sea, Pergamon Press, Oxford, UK, 1987, p. 440.

21 M. A. Farag, D. A. Al-Mahdy, A. Meyer, H. Westphal and L. A. Wessjohann, Metabolomics reveals biotic and abiotic elicitor effects on the soft coral Sarcophyton ehrenbergi terpenoid content, Sci. Rep., 2017, 7, 648.

22 M. A. Farag, A. Porzel, M. A. Al-Hammady, M. E. Hegazy, A. Meyer, T. A. Mohamed, H. Westphal and L. A. Wessjohann, Soft Corals Biodiversity in the Egyptian Red Sea: A Comparative MS and NMR Metabolomics Approach of Wild and Aquarium Grown Species, $J$. Proteome Res., 2016, 15, 1274-1287.

23 M. E. Hegazy, A. I. Elshamy, T. A. Mohamed, A. R. Hamed, M. A. Ibrahim, S. Ohta and P. Paré, Cembrene diterpenoids with ether linkages from Sarcophyton ehrenbergi: an anti-proliferation and molecular-docking assessment, Mar. Drugs, 2017, 15, 192.

24 M. E. Hegazy, T. A. Mohamed, A. I. Elshamy, M. A. Alhammady, S. Ohta and P. Paré, Casbane diterpenes from red sea coral Sinularia polydactyla, Molecules, 2016, 21, 308.

25 T. Bruhn, A. Schaumlöffel, Y. Hemberger and G. Bringmann, Chirality, 2013, 25, 243-249.

26 Z. Xi, W. Bie, W. Chen, D. Liu, L. V. Ofwegen, P. Proksch and W. Lin, Sarcophyolides B-E, new cembranoids from the soft coral Sarcophyton elegans, Mar. Drugs, 2013, 11(9), 31863196.
27 F. K. Chan, K. Moriwaki and M. J. De Rosa, Detection of necrosis by release of lactate dehydrogenase activity, Methods Mol. Biol., 2013, 979, 65-70.

28 T. Mosmann, Rapid colorimetric assay for cellular growth and survival: Application to proliferation and cytotoxicity assays, J. Immunol. Methods, 1983, 65, 55-63.

29 A. Dutta, S. Bandyopadhyay, C. Mandal and M. Chatterjee, Development of a modified MTT assay for screening antimonial resistant field isolates of Indian visceral leishmaniasis, Parasitol. Int., 2005, 54, 119-122.

30 OpenEye Scientific Software, OMEGA2.5.1.4, Santa Fe, NM, USA.

31 M. J. Frisch, G. W. Trucks, H. B. Schlegel; G. E. Scuseria, M. A. Robb, J. R. Cheeseman, G. Scalmani, V. Barone, B. Mennucci, G. A. Petersson, H. Nakatsuji, M. Caricato, X. Li, H. P. Hratchian, A. F. Izmaylov, J. Bloino, G. Zheng, J. L. Sonnenberg, M. Hada, M. Ehara, K. Toyota, R. Fukuda, J. Hasegawa, M. Ishida, T. Nakajima, Y. Honda, O. Kitao, H. Nakai, T. Vreven, J. A. Montgomery, J. E. Peralta, F. Ogliaro, M. Bearpark, J. J. Heyd, E. Brothers, K. N. Kudin, V. N. Staroverov, R. Kobayashi, J. Normand, K. Raghavachari, A. Rendell, J. C. Burant, S. S. Iyengar, J. Tomasi, M. Cossi, N. Rega, J. M. Millam, M. Klene, J. E. Knox, J. B. Cross, V. Bakken, C. Adamo, J. Jaramillo, R. Gomperts, R. E. Stratmann, O. Yazyev, A. J. Austin, R. Cammi, C. Pomelli, J. W. Ochterski, R. L. Martin, K. Morokuma, V. G. Zakrzewski, G. A. Voth, P. Salvador, J. J. Dannenberg, S. Dapprich, A. D. Daniels, O. Farkas, J. B. Foresman, J. V. Ortiz, J. Cioslowski and D. J. Fox, Gaussian 09, Gaussian Inc., Wallingford CT, USA, 2009.

32 T. Bruhn, A. Schaumlöffel, Y. Hemberger and G. Pescitelli, SpecDis, Berlin, Germany, 2017. 